\title{
EFEITOS DO SISTEMA DE PREPARO E DA ROTAÇÃO DE CULTURAS NA POROSIDADE E DENSIDADE DO SOLO(1)
}

\author{
L. F.STONE ${ }^{(2)} \&$ P.M. SILVEIRA (2)
}

\begin{abstract}
RESUMO
O trabalho foi realizado na Embrapa Arroz e Feijão, em Santo Antônio de Goiás (GO), em Latossolo Vermelho perférrico, sob pivô central, por seis anos consecutivos, durante os quais se efetuaram 12 cultivos. Estudaram-se os efeitos de quatro sistemas de preparo do solo e seis rotações de culturas sobre a densidade e porosidade do solo. Foi utilizado o delineamento inteiramente casualizado, em parcelas subdivididas, com três repetições. As parcelas foram constituídas pelos sistemas de preparo: arado/grade, arado, grade e plantio di reto e as subparcelas pelas rotações: (a) arroz-feijão, (b) milho-feijão, (c) soja-trigo, (d) soja-trigo-soja-feijão-arroz-feijão, (e) arroz consorciado com calopogônio-feijão e (f) milho-feijão-milho-feijão-arroz-feijão. As rotações a, b, c e e foram anuais e as $\mathrm{d}$ e f, trienais. $\mathrm{O}$ plantio direto ocasionou maior valor de densidade do solo e menores de porosidade total e macroporosidade na camada superficial, enquanto o preparo do solo com grade aradora propiciou o menor valor de densidade e maior de porosidade total. Nas camadas mais profundas, o preparo do solo com arado de ai veca propiciou os menores valores de densidade do solo e maiores de porosidade total e macroporosidade. Na camada superficial do solo, os sistemas de rotação que incluíram soja e trigo levaram a maiores valores de densidade do solo e microporosidade e menores de macroporosidade, enquanto o sistema arroz consorciado com calopogônio-feijão propiciou maior valor de macroporosidade e menor de microporosidade.
\end{abstract}

Termos de indexação: arado de aiveca, grade aradora, plantio direto.

(1) Recebido para publicação em setembro de 1999 e aprovado em dezembro de 2000

(2) Pesquisador da Embrapa Arroz e Feijão. Caixa Postal 179, CEP 75375-000 Santo Antônio de Goiás (GO). Bolsista do CNPq. Email: stone@cnpaf.embrapa.br; pmarques@cnpaf.embrapa.br 


\title{
SUMMARY: EFFECTS OF SOIL TILLAGE SYSTEMS AND CROP ROTATIONS ON SOIL POROSITY AND BULK DENSITY
}

\begin{abstract}
This study, covering 12 cultivations, was carried out at E mbrapa Rice\& Beans Research Center, Santo Antônio de Goiás, Goiás, Brazil, in an Oxisol, under center pivot, for six consecutive years. The effects of four soil tillage systems and six crop rotations on bulk density and soil porosity were evaluated. The experiment was conducted in a completely randomized design, using a splitplot arrangement, with three replications. The tillage treatments were moldboard plough/ harrow disc, moldboard pl ough, harrow disc, and notillage. Tillagetreatments constituted themain plots and rotation treatments, the subpl ots. Thecrop rotations were: (a) upland rice-common bean, (b) corn-common bean, (c) soybeanwheat, (d) soybean-wheat-soybean-common bean-upland ricecommon bean, (e) upl and rice associated to cal opogoni um-common bean, and (f) corn-common bean-corn-common beanupland rice-common bean. Crop rotations $a, b, c$, and e were annuals and $d$ and f were of three years'duration. The soil under no-tillage at the surface layer $(0-10 \mathrm{~cm})$ showed the highest bulk density valueand thelowest total porosity and macroporosity val ues. Whereas thesoil under harrow treatment showed thelowest bulk density and thehighest total porosity values. Under mol dboard plough, the $10-20$ and $20-30 \mathrm{~cm}$ soil layers had the lowest bulk density val ues and thehighest total porosity and macroporosity values. On thesurfacelayer, crop rotations composed by soybean and wheat showed the highest bulk density and microporosity values and thel owest macroporosity values whi lethecrop rotation composed by upland rice associated to calopogonium and common bean showed the highest macroporosity value and the lowest microporosity value.
\end{abstract}

Index terms: moldboard plough, harrow, no-tillage.

\section{NTRODUÇÃO}

A degradação da estrutura afeta o desenvolvimento vegetal e predispõe o solo à erosão hídrica acel erada. O manejo incorreto de máquinas e equipamentos agrícolas, levando à formação de camada subsuperficial compactada, tem sido apontado como uma das principais causas da degradação da estrutura do sol o e do decréscimo da produtividade das culturas (Campos et al., 1995). Os efeitos do preparo do solo sobre sua estrutura dependem da intensidade de revolvimento ou trânsito, tipos de equipamentos utilizados, manejo dos resíduos vegetais e condições do sol o no momento do preparo (Vieira, 1985).

Os Latossolos argilosos do cerrado brasileiro, susceptíveis à compactação, têm sido utilizados com sistemas de preparo que revolvem o solo. Este revolvimento, associado a chuvas intensas, de alta erosividade, e a temperaturas el evadas, degrada rapidamente o solo, comprometendo a sustentabilidade da atividade agrícola.

O sistema de preparo do solo com grade aradora tem sido o mais usado nessa região. Normalmente, a grade trabalha o sol o a baixa profundidade e é de al to rendimento de campo. Entretanto, o uso contínuo desse implemento pode levar à formação de camadas compactadas, chamadas "pé-de-grade" (Silva, 1992). O arado de aiveca é pouco usado porque requer maior tempo e energia para a sua operação que os demais implementos, embora, em situações onde foi usado, tenha ocorrido maior produtividade de milho (Kluthcouski, 1998) e de arroz (Seguy \& Bouzinac, 1992; Kluthcouski, 1998), quando comparadoao plantio direto ou ao preparo com grade aradora. Isto deveu-se ao pior desenvolvimento do sistema radicular nesses sistemas de preparo, por causa da compactação do sol o na camada superficial ou subsuperficial, respectivamente.

A adoção do plantio direto vem expandindo na RegiãoCentral doBrasil. Elepodeser uma alternativa ao sistema convencional de preparo do solo e contribuir para a sustentabilidade de sistemas agrícolas intensivos, por manter o solo coberto por restos culturais ou por plantas vivas o ano inteiro, minimizando os efeitos da erosão, e por manter o teor de matéria orgânica (Albuquerqueet al., 1995).

Entretanto, no plantio direto, os solos apresentam, em geral, na camada superficial, após três a quatro anos, maiores val ores de densidadeemicroporosidade e menores val ores de macroporosidadee porosidade total, quando comparados com os do preparo convencional. Isto decorre, principalmente, do arranjamento natural do solo, quando não é mobilizado, e da pressão provocada pel o trânsito de máquinas e implementos agrícolas, sobretudo quando realizado em solos argilosos e com teores el evados de umidade(Vieira, 1981; Vieira \& Muzilli, 1984; Corrêa, 1985). 
Corroborando tais informações, Derpsch et al. (1991), em Latossolo Roxo, na camada de 0-20 cm, e Urchei (1996), em Latossolo Vermelho-Escuro, na camada de $0-10 \mathrm{~cm}$, constataram que a densidade do solo foi maior e a porosidade total e a macroporosidade foram menores sob plantio direto, em comparação com o preparo com arado de disco. Nas camadas mais profundas, as mai ores densidades do solo ocorreram no preparo com arado de disco, levando à formação de "pé-de-arado".

Contudo, segundo Fernandes et al. (1983) e Reeves (1995), com o passar dos anos, a densidade do sol o sob plantio direto pode diminuir, devido, em parte, ao aumento do teor de matéria orgânica na camada superficial, melhorandoa estrutura do solo. Em condições temperadas, Voorhees \& Lindstrom (1984) verificaram ser necessários de três a quatro anos para um Molissolo franco-argilo-siltoso sob plantio direto apresentar, na camada de 0-15 cm, maior porosidade que o preparado com arado de aiveca. Na camada de $15-30 \mathrm{~cm}$, o tempo necessário foi de sete anos.

A rotação de culturas, pela inclusão de espécies com sistema radicular agressivo e pelos aportes diferenciados de matéria seca, também pode alterar as propriedades físicas do solo. A intensidade da alteração depende do período de cultivo, do número de cultivos por ano e das espécies cultivadas.

Machado et al. (1981) observaram, em L atossolo Vermel ho-Escuro, após oito anos de cultivo convencional da sucessão soja-trigo, que houve redução na porosidade total ena macroporosidadee aumento na mi croporosidade ena densidade do solo, em relação ao solo sob vegetação de mata virgem. Estes resultados foram atribuídos à destruição da estrutura do solo pelo cultivo intensivo, à ação das máquinas agrícolas e à redução no teor de matéria orgânica. Albuquerque et al. (1995), também em Latossolo Vermelho-Escuro, verificaram que, sob manejo convencional ou plantio direto, a densidade do solo na camada de $1,0-8,6 \mathrm{~cm}$ foi maior e a porosi dadetotal menor na sucessão soja-trigo do que nas rotações que incluíam aveia, ervilhaca e milho. Atribuíram este fato à presença da aveia no sistema de rotação, contribuindo para a conservação e restauração da estrutura do solo.

Gomes et al. (1978), em Podzólico VermelhoAmarelo, após 14 anos de cultivo convencional, verificaram maiores valores da densidade do solo na sucessão soja-trigo que na de milho-trigo ou nos cultivos contínuos desoja, trigo ou milho, atribuídos ao uso mais intensivo do solo, duas vezes por ano, e aos tratos culturais inerentes à cultura da soja.

O objetivo deste trabalho foi verificar como diferentes sistemas de preparo do sol o e de rotações de culturas afetam a porosidade e a densidade do solo nas condições do cerrado brasileiro.

\section{MATERIAL E MÉTODOS}

Estetrabal ho foi realizado na Fazenda Capivara, da E mbrapa Arroz eF eijão, localizada no município de Santo Antônio de Goiás (GO), sobre Latossolo Vermelho perférrico e em área irrigada por pivô central.

Esta área, originalmente sob vegetação de cerrado, foi desmatada em 1977, cultivada anualmente, na época das chuvas, com as culturas do milho ou do arroz, e adubada de acordo com as recomendações da Comissão Estadual deF ertilidade deSol os (s.d.). Em 1989, foi instalado um pivôcentral na área. Em novembro deste ano e de 1991, foi semeado milho na área e, em novembro de 1990, semeado arroz. O feijão foi semeado anual mente em junho, a partir de 1989. Em outubro de 1992, iniciouse o experimento. De 1977 a junho de 1992, o sol o da área experimental foi preparado com grade aradora. Em maio de 1989 e de 1992, foram aplicadas 2,5 t ha-1 de calcário, seguindo-se as recomendações de adubação e calagem baseadas na análise de solo e indicadas para as culturas dearroz, soja, milho, feijão e trigo, segundo Comissão de Fertilidade de Solos de Goiás (1988). O experimento foi realizado durante seis anos, setembro de 1992 a setembro de 1998, duranteos quais foram feitos 12 cultivos. Foi utilizado o delineamentointeiramentecasualizado, em parcelas subdivididas (Chacín Lugo, 1997), com três repetições.

Os tratamentos constituíram-se na forma de preparo do solo: (a) aração com arado de aiveca, realizada em novembro-dezembro e grade aradora, em maio-junho (arado/grade); (b) aração com arado de aiveca, em ambos os períodos (arado); (c) aração com grade aradora, em ambos os períodos (grade), e (d) plantio direto. No preparo do solo, de acordo com o tratamento, foram utilizados arado detrês aivecas comuns, operando na profundidade de aproximadamente $30 \mathrm{~cm}$, e grade aradora de 20 discos de $66 \mathrm{~cm}$ de diâmetro, operando de 10 a $15 \mathrm{~cm}$.

Nas subparcelas, estudaram-se os sistemas de rotação deculturas: (a) arroz-feijão (A-F); (b) milhofeijão (M-F); (c) soja-trigo (S-T); (d) soja-trigo-sojafeijão-arroz-feijão (S-T-S-F-A-F); e) arroz consorciado com calopogônio-feijão (A/C-F) e (f) milho-feijãomilho-feijão-arroz-feijão (M-F-M-F-A-F ). As rotações $a, b, c$ e e foram anuais e as $d$ e $f$, trienais. A semeadura do calopogônio foi feita manualmente 30 dias após a do arroz, para evitar a concorrência com esta cultura. As culturas de arroz, soja e milho foram semeadas em novembro-dezembro e as de feijão e trigo, em maio-junho.

Em outubro de 1995, foram aplicadas 2,5 t ha-1 de cal cário em toda a área experimental, o qual foi incorporado ao solo de acordo com o sistema de preparo, até à profundidade de operação dos implementos. No plantio direto, foi aplicado na superfície 
e não foi incorporado. Os adubos foram aplicados no sulco de semeadura, na profundidade de $5-6 \mathrm{~cm}$.

A análise granulométrica do solo, realizada pelo método da pipeta, apresentou valores médios semel hantes entre as profundidades. Os teores de areia, silte e argila foram de 410, 190 e $400 \mathrm{~g} \mathrm{~kg}^{-1}$, respectivamente; classe textural argila.

A determinação da densidadeeda microporosidade do solo foi realizada em amostras indeformadas, col etadas em camadas de 0-10, 10-20 e 20-30 cm, em outubro de 1992, antes do preparo do sol o de verão, e de 1993 a 1998, em setembro, após a col heita das culturas de inverno, com exceção de 1997, quando não foram coletadas amostras. Para obter as amostras, introduziram-se no sol o cilindros de $5 \mathrm{~cm}$ de diâmetro por $5 \mathrm{~cm}$ de altura, de modo a coincidir o meio do cilindro com a metade da profundidade previamente estabelecida. Amostras deformadas também foram retiradas nas mesmas camadas para determinação da densidade de partículas.

A microporosidade foi determinada pel o método da mesa de tensão, a densidade do sol o pel o método do anel volumétrico, a densidade de partículas pelo método do balão volumétrico, a porosidade total pela relação entre a densidade do solo e a densidade de partículas, ea macroporosidade pela diferença entre a porosidade total e a microporosidade, utilizando orientações da EMBRAPA (1997).

Os valores iniciais de densidade do solo, em $\mathrm{Mg} \mathrm{m}^{-3}$, porosidade total, micro e macroporosidade, em $\mathrm{m}^{3} \mathrm{~m}^{-3}$, na camada de $0-10 \mathrm{~cm}$, foram, respectivamente, de 1,30;0,515;0,331 e 0,184. Na camada de 10-20 cm, os val ores foram, respectivamente, de 1,$39 ; 0,481 ; 0,350$ e 0,130 e, na camada de 20 $30 \mathrm{~cm}$, foram de 1,38; 0,482; 0,342 e 0,141.

Foi feita análise de variância conjunta dos anos por profundidade, sendo as médias comparadas pelo teste deTukey, a 5\%, bem como análise deregressão, considerando o número de anos de cultivo.

\section{RESULTADOS E DISCUSSÃO}

A interação ano $x$ sistemas de preparo do solo $x$ sistemas de rotação de culturas foi significativa para todas as propriedades físicas analisadas, em todas as camadas consideradas, provavel mente em decorrência não só das variadas condições climáticas e de doenças e pragas, que condicionaram diferentes desenvolvimentos das culturas e, por conseguinte, diferentes aportes de material vegetal ao solo, mas também da variação anual nas culturas implantadas, de acordo com o esquema de rotação, e da variação anual das condi ções de umidade do sol o no momento do preparo. Contudo, a tendência do comportamento das propriedades físicas foi semel hante ao longo dos anos, assim, para efeito de discussão, foram consideradas as médias dos anos para comparação dos efeitos dos diferentes sistemas de preparo do solo e das rotações de culturas nas propriedades físicas do solo.

A análise de regressão, quando se consideraram os sistemas de rotação de culturas, mostrou que nenhuma das propriedades físicas consideradas apresentou correlação significativa com o número de anos de cultivo. Com relação aos sistemas de preparo do solo, apenas a mi cro ea macroporosidade, noplantio direto, correlacionaram-sesignificativamente com o número de anos de cultivo.

O sol o sob plantio direto, na camada de $0-10 \mathrm{~cm}$, pel o seu não-revolvimento e pela movimentação de máquinas e implementos agrícolas, apresentou maior valor de densidade do solo e menor de porosidade total (Quadro 1), o que concorda com os relatados por Vieira \& Muzilli (1984), Corrêa (1985) eU rchei (1996), caracterizando maior compactação do solo em comparação aos demais sistemas de preparo.

O preparo com grade, por sua vez, propiciou, nessa camada, omenor valor de densidadee o mai or de porosidade total, por mobilizar o solo até $10-15 \mathrm{~cm}$ de profundidade e aliviar, desta forma, a compactação causada pelas operações de manejo das culturas. A pesar das variações verificadas ao longo dos anos, decorrentes das distintas condições de umidade no momento do preparo do solo, dos diferentes tratos culturais aplicados e dos variados aportes de material vegetal das diferentes culturas e suas produtividades, no preparo com grade, os valores de densidade do solo e da porosidade total estiveram, respectivamente, sempreabaixo e acima dos val ores iniciais, ocorrendo o contrário sob plantio direto.

Essa situação difere do observado em condições temperadas por Voorhees \& Lindstrom (1984), que verificaram ter, após três a quatro anos, o solo sob plantio direto apresentado maior porosidade que o preparado com arado de aiveca. No plantio direto, quando o solo permanece coberto por material vegetal todo o tempo, espera-se que haja forte presença dematerial orgânico na camada superficial, promovendo intensa atividade biológica, resultando em produtos que desempenham função na formação e estabilização (agentes cimentantes) dos agregados.

Cabe salientar que, neste experimento, no plantio direto, cada cultura era semeada na resteva da anterior, e as condições climáticas da região, com verão quente e úmi do e inverno com temperaturas médias acima de $20^{\circ} \mathrm{C}$, al iadas à prática da irrigação, favoreciam a rápida mineralização do material orgânico. Não havia cultura específica de cobertura, que poderia contribuir para aumentar o teor de matéria orgânica e reduzir a densidade do solo com o tempo, como observado por Reeves (1995).

Nas camadas de solo de $10-20$ e $20-30 \mathrm{~cm}$ de profundidade, em geral, os valores de densidade do sol o foram menores e os de por osidade total maiores 
no preparo com arado, refletindo a ação de revolvimento mais profunda do implemento.

Silveira et al. (1994) observaram que, após quatro anos de aração a $30 \mathrm{~cm}$ de profundidade, houve redução na densidade do sol o nas profundidades de 20 e 30 cm. O uso da gradelevou à formação decamada mais compactada abaixo da profundidade de atuação doimplemento, aumentando os val ores de densi dade dosol oe reduzindo os de porosidadetotal . O comportamento do preparo alternado com arado e grade, nestas camadas, foi semel hante ao do preparo com grade. Como, no preparo alternado, o preparo com grade era feito em maio-junho e o preparo com arado era feito em novembro-dezembro, ele refletiu mais a ação da grade, pois as amostragens foram feitas em setembro. Smittle\& Threadgill (1977) verificaram aumentos novalor da resistência do solo à penetração após $10 \mathrm{~cm}$, em sol os preparados com gradearadora.

Diferenças significativas entre os sistemas de preparo do solo em relação à microporosidade ocorreram apenas na camada de $0-10 \mathrm{~cm}$ de profundidade (Quadro 1), sendo a microporosidade maior no plantio direto em comparação aos demais preparos (alternado ou com arado). A utilização contínua do plantio direto fez com que, ao longo dos anos, a microporosidade do solo nesta camada aumentasse segundo a equação $Y=0,335+0,008 X$, $r=0,88^{*}$. O solo sob plantio direto apresentou maiores valores de microporosidade que os iniciais em todas as camadas amostradas.

Os sistemas de preparo que revolveram o solo propiciaram, na camada de $0-10 \mathrm{~cm}$, maiores val ores de macroporosidade que o plantio direto (Quadro 1), concordando com os resultados obtidos por Vieira \& Muzilli (1984), Corrêa (1985) e Urchei (1996). Nas demais camadas, o preparo com arado propiciou os maiores valores de macroporosidade. A macroporosidade do solo sob plantio direto, nas camadas de 0-10 e 10-20 cm, diminuiu ao longo dos anos segundo as equações $Y=0,162-0,014 x$, $r=-0,81^{*}$, eY $=0,120-0,011 X, r=-0,81^{*}$, respectivamente, sinalizando um processo de compactação.

A redução da porosidade total e da macroporosidade e o aumento da microporosidade no solo sob plantio direto podem não afetar o desenvolvimento e a distribuição do sistema radicular. Henklain et al. (1996) verificaram que estes fatores foram mel hores sob plantio direto em comparação aos do preparo convencional do solo, graças à qualidade dos poros que, embora menores, apresentavam-se contínuos ao longo do perfil, aos canais e galerias formados pela atividade biológica e decomposição das raízes das culturas anteriores e às fendas provocadas pel os gradientes de umidade.

Voorhees et al. (1989) verificaram, em três solos afetados pela compactação do subsol oe da superfície,

Quadro 1. Valores da densidade do solo, porosidade total, microporosidade e macroporosidade nas camadas de solo de 0-10, 10-20 e 20-30 cm de profundidade, determi nados após as culturas de inverno, em quatro sistemas de preparo do solo e seis sistemas de rotação de culturas

\begin{tabular}{|c|c|c|c|c|c|c|c|c|c|c|}
\hline \multirow{2}{*}{$\begin{array}{l}\text { Característica } \\
\text { física do solo }\end{array}$} & \multicolumn{4}{|c|}{ Sistema de preparo do solo(1) } & \multicolumn{6}{|c|}{ Sistema de rotação de cultura(2) } \\
\hline & $\mathbf{A} / \mathbf{G}$ & A & G & PD & A-F & M-F & S-T & S-T-S-F-A-F & A/C-F & M-F-M-F-A-F \\
\hline & & & & & & $0-10 \mathrm{~cm}$ & & & & \\
\hline Densidade do solo ( $\mathrm{Mg} \mathrm{m}^{-3}$ ) & $1,28 \mathrm{~b}$ & $1,30 \mathrm{~b}$ & $1,24 \mathrm{c}$ & $1,39 a$ & $1,30 a b c$ & $1,29 \mathrm{bc}$ & $1,33 \mathrm{a}$ & $1,32 \mathrm{ab}$ & $1,28 \mathrm{bc}$ & $1,27 \mathrm{c}$ \\
\hline Porosidade total $\left(\mathrm{m}^{3} \mathrm{~m}^{-3}\right)$ & $0,517 \mathrm{~b}$ & $0,505 \mathrm{c}$ & 0,532 a & $0,469 d$ & $0,507 a b$ & $0,510 a b$ & $0,497 \mathrm{~b}$ & $0,499 a b$ & $0,510 a b$ & $0,512 a$ \\
\hline Microporosidade $\left(\mathrm{m}^{3} \mathrm{~m}^{-3}\right)$ & $0,348 \mathrm{bc}$ & $0,336 c$ & $0,364 a b$ & $0,372 \mathrm{a}$ & $0,355 a b$ & $0,361 a b$ & 0,368 a & $0,366 a$ & $0,331 \mathrm{c}$ & $0,350 \mathrm{~b}$ \\
\hline \multirow[t]{2}{*}{ Macroporosidade $\left(\mathrm{m}^{3} \mathrm{~m}^{-3}\right)$} & $0,169 a$ & 0,168 a & $0,168 \mathrm{a}$ & $0,098 \mathrm{~b}$ & $0,153 \mathrm{~b}$ & 0,148 bc & $0,129 d$ & $0,133 \mathrm{dc}$ & $0,180 \mathrm{a}$ & $0,162 a b$ \\
\hline & \multicolumn{10}{|c|}{$10-20 \mathrm{~cm}$} \\
\hline Densidade do solo $\left(\mathrm{Mg} \mathrm{m}^{-3}\right)$ & $1,42 \mathrm{a}$ & $1,35 \mathrm{~b}$ & $1,43 a$ & $1,44 \mathrm{a}$ & $1,38 \mathrm{c}$ & $1,43 a$ & $1,40 \mathrm{bc}$ & $1,42 \mathrm{a}$ & $1,42 \mathrm{a}$ & $1,41 \mathrm{ab}$ \\
\hline Porosidade total $\left(\mathrm{m}^{3} \mathrm{~m}^{-3}\right)$ & $0,452 \mathrm{~b}$ & $0,482 a$ & $0,448 \mathrm{~b}$ & $0,440 \mathrm{~b}$ & $0,463 a$ & $0,441 \mathrm{~b}$ & $0,458 a$ & $0,458 a$ & $0,456 a$ & $0,457 a$ \\
\hline Microporosidade $\left(\mathrm{m}^{3} \mathrm{~m}^{-3}\right)$ & 0,365 & 0,368 & 0,373 & 0,371 & 0,369 & 0,361 & 0,376 & 0,369 & 0,367 & 0,374 \\
\hline \multirow[t]{2}{*}{ Macroporosidade $\left(\mathrm{m}^{3} \mathrm{~m}^{-3}\right)$} & $0,087 \mathrm{~b}$ & 0,114 a & $0,075 b c$ & $0,069 \mathrm{c}$ & 0,094 & 0,079 & 0,082 & 0,089 & 0,089 & 0,084 \\
\hline & \multicolumn{10}{|c|}{$20-30 \mathrm{~cm}$} \\
\hline Densidade do solo ( $\mathrm{Mg} \mathrm{m}^{-3}$ ) & $1,43 a$ & $1,38 \mathrm{~b}$ & $1,46 \mathrm{a}$ & $1,42 \mathrm{ab}$ & 1,41 & 1,43 & 1,43 & 1,43 & 1,42 & 1,42 \\
\hline Porosidade total $\left(\mathrm{m}^{3} \mathrm{~m}^{-3}\right)$ & $0,445 \mathrm{~b}$ & $0,470 a$ & $0,433 \mathrm{~b}$ & $0,451 b$ & $0,452 a$ & $0,446 a b$ & $0,451 a b$ & $0,441 \mathrm{~b}$ & $0,455 a$ & $0,454 a$ \\
\hline Microporosidade $\left(\mathrm{m}^{3} \mathrm{~m}^{-3}\right)$ & 0,363 & 0,368 & 0,370 & 0,380 & $0,361 \mathrm{~b}$ & $0,369 a b$ & 0,385 a & $0,372 a b$ & 0,362 b & $0,374 a b$ \\
\hline Macroporosidade $\left(\mathrm{m}^{3} \mathrm{~m}^{-3}\right)$ & $0,082 \mathrm{~b}$ & 0,102 a & $0,063 \mathrm{~b}$ & $0,070 \mathrm{~b}$ & 0,091 a & $0,077 a b$ & $0,066 \mathrm{~b}$ & $0,069 \mathrm{~b}$ & 0,093 a & $0,080 a b$ \\
\hline
\end{tabular}

Médias seguidas pela mesma letra, na linha, dentro de preparo do solo ou de rotação de culturas, não apresentam diferenças significativas a $5 \%$ pelo teste de Tukey.

(1) Médias de seis sistemas de rotação, cinco anos e três repetições, A/G - arado/grade, A - arado, G - grade e PD- plantio direto.

(2) Médias de quatro sistemas de preparo do solo, cinco anos e três repetições, A - arroz, F - feijão, M - milho, S - soja, T - trigo e A/

C - arroz consorciado com calopogônio. 
que as diferenças na produtividade de milho em relação ao solo não compactado eram variáveis, dependendo das condições climáticas, indicando que, em algumas situações, a maior densidade do solo pode não ser prejudicial à produtividade das culturas. Stone \& Silveira (1999) relataram que, mesmo propiciando maior compactação do solo até $15-22 \mathrm{~cm}$ de profundidade, as produtividades do feijoeiro sob plantio direto foram superiores ou similares às obtidas com preparo do solo com grade ou com arado.

Os efeitos dos sistemas de rotação de culturas sobre as propriedades físicas do solo, ao longo dos anos, foram mais variáveis que os dos sistemas de preparo do solo. Provavelmente isto ocorreu devido às variadas condições climáticas e fitossanitárias, que condicionaram diferentes aportes de material vegetal ao solo, e à variação anual nas culturas implantadas, de acordo com o esquema de rotação. Entretanto, pode-se observar que o sistema que incluiu soja etrigo propiciou, na camada de 0-10 cm de profundidade, maior valor de densidade do solo que os sistemas com milho e feijão ou arroz consorciado com calopogônio e feijão (Quadro 1).

Com relação à porosidade total, contudo, o sistema soja-trigo diferiu significativamenteapenas dosistema M-F-M-F-A-F , apresentandovalor menor. Entre as culturas estudadas, a do trigo éa semeada no menor espaçamento, o quecondiciona a passagem das rodas compactadoras em maior área de solo. Além disto, segundo Fahad et al. (1982), a soja tem efeito negativo na agregação do solo. Gomes et al. (1978) verificaram mai ores valores da densidade do solo na sucessão soja-trigo que na milho-trigo ou nos cultivos contínuos de soja, trigo ou milho. Al buquerque et al . (1995) verificaram quea sucessão soja-trigo propiciou maiores valores de densidade do solo na camada superficial que as rotações que incluíam outras culturas como a aveia, ervilhaca e milho. Na camada de $10-20 \mathrm{~cm}$ de profundidade, a densidade do sol o foi menor no sistema arroz-feijão. Nesta camada, o menor valor de porosidade total foi verificado no sistema milho-feijão e, na camada de 20-30 cm, no sistema S-T-S-F-A-F .

A microporosidade, na camada de sol o de $0-10 \mathrm{~cm}$ de profundidade, de maneira geral, apresentou menor valor no sistema A/C-F emai ores nos sistemas que incluíram soja e trigo (Quadro 1). Na camada de $20-30 \mathrm{~cm}$ de profundidade, o sistema soja-trigo também propiciou alto valor de microporosidade. Machado et al. (1981) também verificaram ter este sistema aumentado a mi croporosi dade do sol o após oito anos de cultivo convencional .

Na camada de $0-10 \mathrm{~cm}$ de profundidade, osistema que propiciou menor val or de microporosidade, A/C$\mathrm{F}$, apresentou o maior valor de macroporosidade (Quadro 1), provavelmente por causa da presença do cal opogônio no sistema. Os sistemas que incluíram soja e trigo apresentaram os menores valores de macroporosidade, tanto nessa camada como na de 20-30 cm de profundidade. Fahad et al. (1982) e Bruce et al. (1990) observaram menores valores de macroporosidade após o cultivo contínuo de soja, em relação ao cultivo contínuo de sorgo ou à rotação da soja com sorgo ou milho. Machado et al. (1981) também encontraram redução na macroporosidade do solo, após oito anos do sistema soja-trigo.

\section{CONCLUSÕES}

1. O não-revolvimento ocasionou maior compactação da camada superficial do solo sob plantio direto, em comparação aos demais sistemas de preparo, evidenciada pelo maior valor de densidade do solo e menores de porosidade total e macroporosidade, enquanto o revolvimento superficial do solo pela grade aradora propiciou o menor valor de densidade e o maior de porosidade, mas levou à formação de camada mais compactada abai xo da profundidade de atuação do implemento.

2. A maior mobilização do solo pelo arado de aiveca reduziu sua compactação nas camadas mais profundas, em comparação aos demais sistemas de preparo, propiciando menores val ores de densidade do solo e maiores de porosidade total e macroporosidade.

3. Os sistemas de rotação de culturas que incluíram soja etrigo provocaram maior compactação da camada superficial do solo, enquanto o sistema arroz consorciado com calopogônio-feijão propiciou maior valor de macroporosidade e menor de microporosidade.

\section{LITE RATURA CITADA}

ALBUQUERQUE, J.A.; REINERT, D.J .; FIORIN, J .E.; RUEDELL, J .; PETRERE, C. \& FONTINELLI, F. Rotação de culturas e sistemas de manejo do solo: efeito sobre a forma da estrutura do solo ao final de sete anos. R. Bras. Ci. Solo, 19:115-119, 1995.

BRUCE, R.R.; LANGDALE, G.W. \& DILLARD, A.L. Tillage and crop rotation effect on characteristics of a sandy surface soil. Soil Sci. Soc. Am. J ., 54:1744-1747, 1990.

CAMPOS, B.C.; REINERT, D.J .; NICOLODI, R.; RUEDELL, J .; PETRERE, C. Estabilidade estrutural de um Latossolo Vermelho-Escuro distrófico após sete anos de rotação de culturas e sistemas de manejo de solo. R. Bras. Ci. Solo, 19:121-126, 1995.

CHACÍN LUGO, F.B. Cursos de avances recientes en el diseñoy análisis de experimentos. S.I., Universidad Central da Venezuela. Facultad de Agronomía, 1997. 145p. 
COMISSÃO ESTADUAL DE FERTILIDADE DE SOLOS. Recomendações defertilizantes para Goiás: 4⿳a aproximação. Goiânia, EMATER-GO, s.d. 54p.

COMISSÃO DE FERTILIDADE DE SOLOS DE GOIÁS - CFSGO . Recomendações de corretivos e fertilizantes para Goiás: 5a aproximação. Goiânia, Universidade Federal de Goiás, 1988. 101p. (Convênio I nformativo Técnico, 1).

CORRÊA, J.C. Efeito de métodos de cultivo em algumas propriedades físicas de um Latossolo Amarelo muito argiloso do estado do Amazonas. Pesq. Agropec. Bras., 20:1317-1322, 1985.

DERPSCH, R.; ROTH, C.H.; SIDIRAS, N. \& KÖPKE, U. Controle da erosão no Paraná, Brasil: sistemas de cobertura do solo, plantio direto e preparo conservacionista do solo. Eschborn, GTZ, 1991. 272p.

EMPRESA BRASILEIRA DE PESQUISA AGROPECUÁRIA EMBRAPA. Serviço Nacional de Levantamento e Conservação de Solos. Manual de métodos de análise de solos. 2.ed. Rio de J aneiro, 1997. 212p.

FAHAD, A.A.; MIELKE, L.N.; FLOWERDAY, A.D. \& SWARTZENDRUBER, D. Soil physical properties as affected by soybean and other cropping sequences. Soil Sci. Soc. Am. J ., 46:377-381, 1982.

FERNANDES, B.; GALLOWAY, H.M.; BRONSON, R.D. \& MANNERING, J .V. Efeito de três sistemas de preparo do solo na densidade aparente, na porosidade total e na distribuição dos poros, em dois solos (Typic Argiaquoll e Typic Hapludalf). R. Bras. Ci. Solo, 7:329-333, 1983.

GOMES, A.S.; PATELLA. J .F. \& PAULLETTO, E.A. Efeitos de sistemas e tempo de cultivo sobre a estrutura de um solo PodzólicoVermelhoAmarelo. R. Bras. Ci. Solo, 2:17-21, 1978.

HENKLAIN,J .C.; GUIMARÃES, M.F.; VIEIRA, M.J . \& MEDINA, C.C. Efeito do preparo do sol o no desenvol vimento radicular. In: CONGRESSO BRASILEIRO DE PLANTIO DIRETO PARA UMA AGRICULTURA SUSTENTÁVEL, 1., Ponta Grossa, 1996. Resumos expandidos. Ponta Grossa, I nstituto Agronômico do Paraná, 1996. p.103-105.

KLUTHCOUSKI, J . Efeito do manejo em alguns atributos de um Latossolo Roxo sob cerrado e nas características produtivas do milho, soja, arroz e feijão, após oito anos de plantio direto. Piracicaba, Escola Superior de Agricultura Luiz de Queiroz, 1998. 180p. (Tese de Doutorado)

MACHADO, J .A.; SOUZA, D.M. \& BRUM, A.C.R. Efeito de anos de cultivo convencional em propriedades físicas do solo. R. Bras. Ci. Solo, 5:187-189, 1981.
REEVES, D.W. Soil management under no-tillage: soil physical aspects. In: SEMINÁRIO INTERNACIONAL DO SISTEMA PLANTIO DIRETO, 1., PassoFundo, 1995. Resumos. Passo Fundo, Empresa Brasileira de Pesquisa Agropecuária Centro Nacional de Pesquisa de Trigo, 1995. p.127-130.

SEGUY, L. \& BOUZINAC, S. Arroz de sequeiro na fazenda Progresso: $4.550 \mathrm{~kg} / \mathrm{ha}$. Piracicaba, POTAFOS, 1992. p.13. (POTAFOS. I nformações Agronômicas, 58)

SILVA, J .G. Ordens de gradagem e sistemas de aração do sol o: desempenho operacional, alterações na camada mobilizada e respostas do feijoeiro (Phaseol us vulgaris L.). Botucatu, Universidade Estadual de São Paulo, 1992. 180p. (Tese de Doutorado)

SILVEIRA, P.M.; SILVA, S.C.; SILVA, O.F . \& DAMACENO, M.A. Estudo desistemas agrícolas irrigados. Pesq. Agropec. Bras., 29:1243-1252, 1994.

SMITTLE, D.A. \& THREADGI LL, E.D. Response of southernpea (Vigna unguiculata L.) to tillage methods. Hortscience, 12:556-558, 1977.

STONE, L.F. \& SILVEIRA, P.M. Efeitos do sistema de preparo na compactação do solo, disponibilidade hídrica e comportamento do feijoeiro. Pesq. Agropec. Bras., 34:8391, 1999.

URCHEI, M.A. E feitos do plantio direto e do preparo convencional sobre alguns atributos físicos de um Latossolo VermelhoEscuro argiloso e no crescimento e produtividade do feijoeiro (Phaseolus vulgaris L.) sob irrigação. Botucatu, Universidade Estadual de São Paulo, 1996. 150p. (Tese de Doutorado)

VIEIRA, M.J . \& MUZILLI, O. Características físicas de um Latossolo Vermelho-Escuro sob diferentes sistemas de manejo. Pesq. Agropec. Bras., 19:873-882, 1984.

VIEIRA, M.J . Comportamento físico do solo em plantio direto. In: FANCELLI, A.L.; TORRADO, P.V. \& MACHADO, J., coords. Atualização em plantio direto. Campinas, Fundação Cargill, 1985. p.163-179.

VIEIRA, M.J. Propriedades físicas do solo. In: INSTITUTO AGRONÔMICO DO PARANÁ. Plantio direto no Estado do Paraná. Londrina, 1981. p.19-32. (IAPAR. Circular, 23)

VOORHEES, W.B.;J OHNSON,J J.F.;RANDALL, G.W. \& NELSON, W.W. Corn growth and yield as affected by surface and subsoil compaction. Agron. J ., 81:294-303, 1989.

VOORHEES, W.B. \& LINDSTROM, M.J . Long-term effects of tillage method on soil tilth independent of wheel traffic compaction. Soil Sci. Soc. Am. J ., 48:152-156, 1984. 
